RESEARCH

\title{
THE ETIOLOGY OF UNILATERAL AND BILATERAL BLINDNESS IN THE ELDERLY AND THE DIFFERENCES BY GENDER
}

Turkish Journal of Geriatrics

DOI: 10.31086/tjgeri.2021.215

2021; 24(2): 196-203

- Nilgün ÖZKAN AKSOY1

- Özlem BURSALI ${ }^{1}$

- Burçin ÇAKIR ${ }^{1}$

- Emine DOĞAN ${ }^{1}$

- Erkan ÇELIK ${ }^{1}$

- Gürsoy ALAGÖZ1
CORRESPONDANCE

${ }^{1}$ Nilgün ÖZKAN AKSOY

Sakarya University Training and Research

Hospital, Sakarya Üniversitesi Tıp

Fakültesi Eğtitim ve Araşıtrma Hastanesi,

Ophthalmology Department, Sakarya, Turkey

Phone: +905053149327

e-mail: nilgun_ozkan@yahoo.com

Received: Jan 30, 2021

Accepted: Apr 07, 2021

1 Sakarya University Training and Research Hospital, Sakarya Üniversitesi Tip Fakültesi Eğtitim ve Araştırma Hastanesi, Ophthalmology Department, Sakarya, Turkey

\section{Abstract}

Introduction: The aim of this study was to investigate the causes of unilateral and bilateral blindness in elderly patients and to evaluate its distribution by gender.

Materials and Methods: Data from 22055 patients examined in the Ophthalmology Department between 2013-2020 were retrospectively analyzed. Patients 65 years or older were selected, and the causes of unilateral and bilateral blindness were evaluated. The patients were divided into two groups: 65-74 years old were presenile and 75 years or older were senile group. The factors causing blindness were evaluated separately by gender and age group.

Results: 452 patients (213 females, 239 males) were 65 years or older with unilateral and bilateral low vision. A total of 193(42.7\%) were in the presenile, and $259(57.3 \%)$ were in the senile group. Age-related macular degeneration was the most common cause of unilateral and bilateral blindness in both genders, followed by diabetic retinopathy in females and glaucoma in males. The most common cause of blindness in both presenile and senile groups was age-related macular degeneration, followed by diabetic retinopathy in the presenile, glaucoma in the senile group.

Conclusions: In the presenile and senile groups, age-related macular degeneration was the most common cause of unilateral and bilateral blindness in females and males. Other leading causes were diabetic retinopathy in females and glaucoma in males.

Keywords: Blindness; Aged; Gender Identity 


\section{INTRODUCTION}

According to the World Health Organization $(\mathrm{WHO})$, at least 2.2 billion people globally have visual impairment or blindness. Of those, over 1 billion cases could have been prevented. Although visual impairment can affect people of all ages, the majority are over the age of 50 . An increased risk of visual impairment is expected with population growth and aging (1, 2).

According to the $\mathrm{WHO}$, the leading causes of visual impairment are often preventable, including uncorrected refractive errors and cataracts. AMD, glaucoma, and diabetic retinopathy (DRP) are other causes. Several studies reported that the incidence of blindness increases with age (3-6).

The causes and incidence of blindness and visual impairment vary in different societies based on their level of development (7). For example, blindness due to cataracts is more frequent in low- and middle-income countries than high-income countries. Diseases such as DRP, glaucoma, and AMD are more common in high-income countries (1).

Low vision and blindness in middle and old age are critical public health problems affecting all aspects of life, including daily personal activities, interaction with society, and access to public services. Adverse effects include a deterioration in the quality of life, falls, and even death $(1,8)$. It is essential to determine the preventable causes of blindness due to cultural, socioeconomic, and demographic differences (3). One of the most important demographic characteristic is gender and the differences in blindness etiology according to this parameter was not assessed in Turkish geriatric population.

The quality of the life might be affected by unilateral and bilateral blindness in geriatric population and to find out the etiologies of blindness might help to detect the preventable ones. Our study aimed to determine the causes of unilateral and bilateral blindness in the senior age groups and determine the differences in impacts between fe- males and males. In addition, the causes of blindness were examined separately in the presenile and senile groups.

\section{MATERIALS AND METHODS}

In this study, data from 22055 patients examined in the Ophthalmology Department between March 2013 and January 2020 were retrospectively analyzed. Best-corrected visual acuity (BCVA) $\leq 0,05$ (measurement by the Snellen chart) in one eye was defined as unilateral, and in both eyes was defined as bilateral blindness $(1,9)$. Among these data, patients 65 years or older were selected; and the causes of unilateral and bilateral blindness were evaluated. In addition, patients were divided into two groups according to age: ages 65-74 were presenile and 75 years or older were senile.

Prior approval was received from the Institutional Review Board (Ethical Board, IRB number: 71522473/050.01.04/25). This retrospective study was performed in accordance with the Declaration of Helsinki 1964 and its later amendments or comparable ethical standards.

The patients' demographic characteristics, detailed ophthalmologic examination, including BCVA measurement and the Snellen chart, slitlamp biomicroscopy, fundus observation, and other systemic diseases were analyzed. Snellen metric converting chart was used for the assessment of patients who have BCVA values lower than 0.05. Etiological factors evaluated included cornea, lens, and retinal diseases such as AMD, DRP, retinal vascular occlusion, degenerative myopia, retinal detachment, retinitis pigmentosa, optic nerve diseases such as glaucoma and optic neuropathy, genetically inherited diseases, strabismus, and uveitis causing blindness. If more than one condition was present in the same patient, the condition causing the most visual impairment was recorded according to $\mathrm{WHO}$ guidelines. Patients with a follow-up period of less than one year were not included in the study. 
The causes of unilateral and bilateral blindness were evaluated and compared between female and male groups and the presenile and senile groups separately.

SPSS (Statistical Package for Social Sciences Inc., Chicago, IL, USA) 23.0 Windows program was used for the statistical analysis. Sex, unilaterality-bilaterality, etiological diagnosis, and frequencies between groups were compared using the Chi-square test. The suitability of the variables for normal distribution was examined using visual and analytical methods. Descriptive analyses were conducted using means and standard deviations for normally distributed variables. Age-dependent values showed normal distribution, so they were compared with the Student's t-test (Independent Samples Test). The $p$-value was less than 0,05 and statistically significant.

\section{RESULTS}

In this study, data from 22055 patients were analyzed and 3372 of these patients were in presenil and senil age groups. Geriatric patients with blindness comprised $2.05 \%$ of the total. There were 452 patients over 65 years of age with unilateral and bilateral low vision. Of the total, 193 (42.7\%) were presenile, and 259 (57.3\%) were senile, and 303 (67.04\%) had unilateral, and 149 (32.96\%) had bilateral blindness.

The mean age of the patients 65 to 95 years old was $76.73 \pm 7.63$. Of the total, 213 (47.1\%) were female, and 239 (52.9\%) were male. The mean age was $76.98 \pm 7.67$ for the females and $76.51 \pm 7.60$ years for the males. Gender groups were similar in terms of age ( $p: 0.654$, Independent Samples Test).

The BCVA was $0.03 \pm 0.01$ in males and $0.02 \pm$ 0.01 in females. There was no statistically significant difference between genders (p: 0.666).

The causes of unilateral and bilateral blindness are shown in Figure 1 and the causes by gender are summarized in Table 1.

Overall, the most common causes of blindness were AMD at $38.9 \%$, DRP at $14.2 \%$, and glaucoma at $11.3 \%$. The causes of unilateral and bilateral blindness were similar in both genders ( $p$ : 0.337, Chisquare).

Figure 1. Causes of unilateral and bilateral blindness

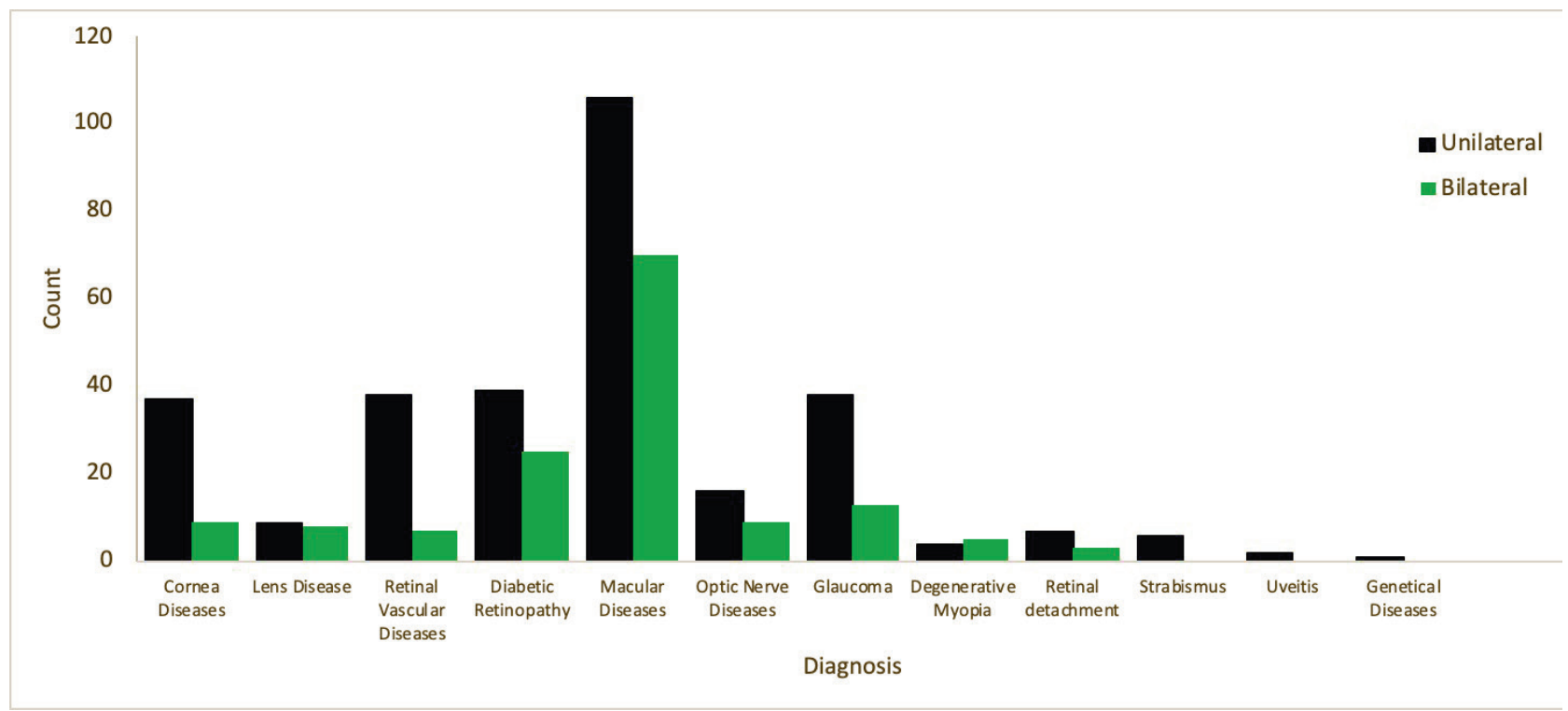


Table 1. Causes of unilateral and bilateral blindness of males and females

\begin{tabular}{|c|c|c|c|c|c|}
\hline \multirow{3}{*}{ Diagnosis } & \multicolumn{4}{|c|}{ Gender } & \multirow{3}{*}{ Total } \\
\hline & \multicolumn{2}{|c|}{ Females $n=213(47,1 \%)$} & \multicolumn{2}{|c|}{ Males $\mathrm{n}=239(52,9 \%)$} & \\
\hline & $\begin{array}{c}\text { Unilateral } \\
137(\% 30.4)\end{array}$ & $\begin{array}{c}\text { Bilateral } \\
75(\% 16.6)\end{array}$ & $\begin{array}{c}\text { Unilateral } \\
165(\% 36.6)\end{array}$ & $\begin{array}{c}\text { Bilateral } \\
74(\% 16.4)\end{array}$ & \\
\hline \multirow{2}{*}{ Age related Macular Diseases } & \multicolumn{2}{|c|}{$82(18,1 \%)$} & \multicolumn{2}{|c|}{$94(20,8 \%)$} & \multirow{2}{*}{$176(38,9 \%)$} \\
\hline & 49 & 33 & 57 & 37 & \\
\hline \multirow{2}{*}{ Diabetic Retinopathy } & \multicolumn{2}{|c|}{$37(8,2 \%)$} & \multicolumn{2}{|c|}{$27(6,0 \%)$} & \multirow{2}{*}{$64(14,2 \%)$} \\
\hline & 20 & 17 & 19 & 8 & \\
\hline \multirow{2}{*}{ Glaucoma } & \multicolumn{2}{|c|}{$22(4,9 \%)$} & \multicolumn{2}{|c|}{$29(6,4 \%)$} & \multirow{2}{*}{$51(11,3 \%)$} \\
\hline & 19 & 3 & 19 & 10 & \\
\hline \multirow[b]{2}{*}{ Corneal diseases } & \multicolumn{2}{|c|}{$17(3,8 \%)$} & \multicolumn{2}{|c|}{$29(6,4 \%)$} & \multirow[b]{2}{*}{$46(10,2 \%)$} \\
\hline & 13 & 4 & 24 & 5 & \\
\hline \multirow{2}{*}{ Retinal vascular diseases } & \multicolumn{2}{|c|}{$19(4,2 \%)$} & \multicolumn{2}{|c|}{$26(5,8 \%)$} & \multirow{2}{*}{$45(10,0 \%)$} \\
\hline & 17 & 2 & 21 & 5 & \\
\hline \multirow{2}{*}{ The other diseases of optic nerve } & \multicolumn{2}{|c|}{$13(2,9 \%)$} & \multicolumn{2}{|c|}{$12(2,7 \%)$} & \multirow{2}{*}{$25(5,5 \%)$} \\
\hline & 7 & 6 & 9 & 3 & \\
\hline \multirow{2}{*}{ Diseases of lens } & \multicolumn{2}{|c|}{$8(1,8 \%)$} & \multicolumn{2}{|c|}{$9(2,0 \%)$} & \\
\hline & 3 & 5 & 6 & 3 & $17(3,8 \%)$ \\
\hline & & & & & \\
\hline Retinal detachment & 2 & 2 & 5 & 1 & $10(2,2 \%)$ \\
\hline & & & & & 9 \\
\hline Degenterative myopla & 3 & 3 & 1 & 2 & $(2,0 \%)$ \\
\hline & & & & & 6 \\
\hline Strabismus & 4 & 0 & 2 & - & $(1,3 \%)$ \\
\hline & & & & & 2 \\
\hline Uveltis & 1 & 0 & 1 & - & $(0,4 \%)$ \\
\hline & & & & & 1 \\
\hline Genetically transmitted diseases & & & 1 & - & $(0,2 \%)$ \\
\hline & 213 & ,1\%) & 239 & & \\
\hline Total & 138 & 75 & 165 & 74 & $452(100,0 \%)$ \\
\hline
\end{tabular}


Table 2. Gender and unilateral-bilateral blindness in presenile and senile groups

\begin{tabular}{|l|c|c|c|}
\hline & $\begin{array}{c}\text { Presenile group } \\
\text { (65-74 yaş) } \\
\mathbf{n}=193(\% 42.7)\end{array}$ & $\begin{array}{c}\text { Senile group } \\
\text { (75 yaş ve üzeri) } \\
\mathrm{n=259}(\% 57.3)\end{array}$ & $\begin{array}{c}\mathbf{P} \\
\text { (Chi-Square) }\end{array}$ \\
\hline $\begin{array}{l}\text { Female/ Male } \\
\text { (n: 213/239) }\end{array}$ & $\begin{array}{c}\text { 87/106 } \\
(\% 19.2-\% 23.5)\end{array}$ & $\begin{array}{c}126 / 133 \\
(\% 27.9-\% 29.4)\end{array}$ & 0.505 \\
\hline Unilateral/Bilateral(n) & $\begin{array}{c}161 / 98 \\
(\% 35.6-\% 21.7)\end{array}$ & $\mathbf{0 . 0 1 2}$ \\
\hline
\end{tabular}

AMD was the most common cause of unilateral and bilateral blindness in both sexes $(18.1 \%$ in females and $20.8 \%$ in males). AMD was followed by DRP (8.2\%) and glaucoma (4.9\%) in females and glaucoma (6.4\%), and corneal diseases $(6.4 \%)$ in males (Figure 2).

The most common causes of unilateral blindness were $A M D, D R P$, and glaucoma in females; AMD, corneal and retinal vascular diseases in males, respectively.
The most common causes of bilateral blindness in females were AMD, DRP, optic nerve diseases. $A M D$, glaucoma, and DRP were the most common causes of bilateral blindness in males.

As shown in Table 2, there was no difference between genders in the presenile and senile groups (p: 0.505 chi-squares). Unilateral and bilateral blindness were observed more frequently in the senile group and statistically significant (p: 0.012 chisquares). The causes of blindness in these groups are summarized in Table 3.

Figure 2. Causes of blindness in male and female genders

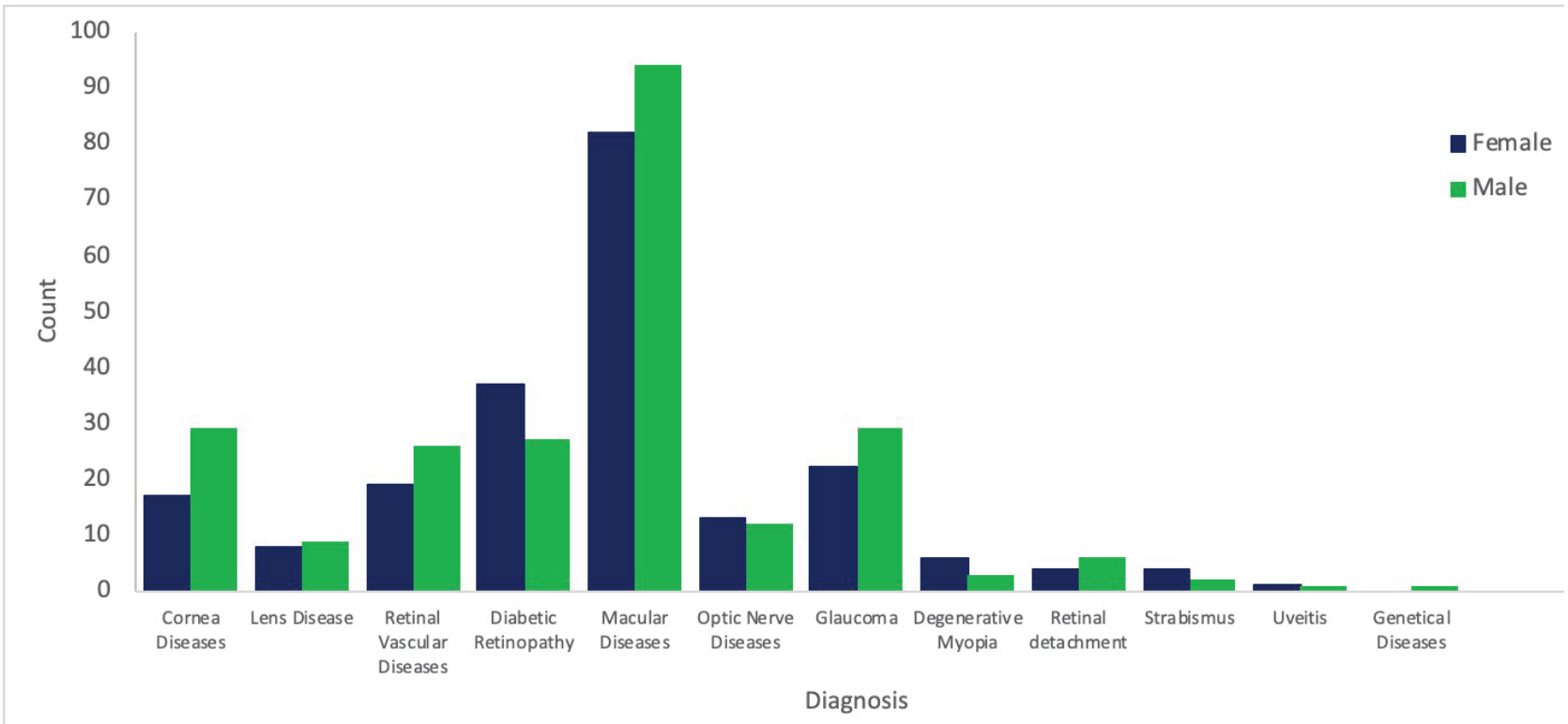




\section{DISCUSSION}

Increasing life expectancy and an aging population raise individual and socioeconomic challenges. One of the systems most affected by advanced age is the visual system (3). It is essential to determine the causes to improve quality of life and economic prosperity (10). Cataracts was the leading cause of visual impairment with $51 \%$ consistent with global data on low vision (11).

Our study demonstrated that, in the presenile and senile groups, AMD was the most common cause of unilateral and bilateral blindness in both females and males. The other leading causes were DRP in females and glaucoma in males. Similar to our results, Tunay et al. reported that AMD was the most common cause of low vision in the senior age group. DRP was the most common cause in the presenile group, and glaucoma was the most common cause in the senile group (3). In a study conducted by Mirza et al., the leading cause of unilateral-bilateral blindness in presenile and senile age groups was cataracts (12). Klaver et al. reported that AMD was the most common cause of blindness in the presenile and senile groups; this was followed by glaucoma, cataracts, optic neuropathy, and myopic degeneration (13).

In this study, the most common causes of blindness were AMD, retinal vascular diseases, and DRP in the presenile group. In the senile group, they were AMD, glaucoma, and corneal diseases. After AMD, the common causes of blindness in the presenile age group were systemic diseases; in the senile age group, the most common cause was ocular diseases. These results may be related to the high number of deaths from systemic diseases in the presenile period.

In another study, no difference was found between genders in patients aged 50-69 and over 70 years in the frequency of blindness (10). Similarly, Esteban et al. found no significant difference between genders in the frequency of blindness (14). Zetterberg et al. reported that $2 / 3$ of the patients they observed due to blindness were women. Similarly, Klaver et al. reported a 75\% higher incidence

Table 3. Causes of blindness in presenile and senile groups

\begin{tabular}{|c|c|c|c|}
\hline & & $\begin{array}{c}\text { Presenile group } \\
\text { (65-74 years) } \\
n=193 \text { (\%42.7) }\end{array}$ & $\begin{array}{c}\text { Senile group } \\
(\geq 75 \text { years }) \\
n=259(\% 57.3)\end{array}$ \\
\hline \multirow{12}{*}{ Diagnosis } & Age related Macular Diseases & $59(\% 13.1)$ & $117(\% 25.9)$ \\
\hline & Diabetic Retinopathy & $47(\% 10.4)$ & $17(\% 3.8)$ \\
\hline & Glaucoma & $19(\% 4.2)$ & $32(\% 7.1)$ \\
\hline & Corneal diseases & $16(\% 3.5)$ & $30(\% 6.6)$ \\
\hline & Retinal vascular diseases & $22(\% 4.9)$ & $23(\% 5.1)$ \\
\hline & The other diseases of optic nerve & $15(\% 3.3)$ & $10(\% 2.2)$ \\
\hline & Diseases of lens & $4(\% 0.9)$ & $13(\% 2.9)$ \\
\hline & Retinal detachment & $2(\% 0.4)$ & $8(\% 1.8)$ \\
\hline & Degenerative myopia & $2(\% 0.4)$ & $7(\% 1.5)$ \\
\hline & Strabismus & $5(\% 1.1)$ & $1(\% 0.2)$ \\
\hline & Uveitis & $2(\% 0.4)$ & - \\
\hline & Genetically transmitted diseases & & $1(\% 0.2)$ \\
\hline
\end{tabular}


of blindness in women $(13,15)$. Khanna et al. concluded that aging and female gender were the risk factors for blindness (16). The differences between women's and men's daily lives and physical conditions, including access to adequate healthcare increased the incidence of diseases that cause blindness in women (17). In our study groups, the number of females (47.1\%) and males (52.9\%) in the presenile and senile groups and the unilateral and bilateral groups were similar. These varying results might be related to demographic and cultural differences.

In a 2015 study, the causes of blindness and low vision were examined in all age groups. While the incidence of cataracts and DRP was higher in women, the frequency of glaucoma and corneal opacity was higher in men. The frequency of AMD was found to be equal for both genders (8). The frequency of AMD in our study was similar. The next leading causes were DRP and glaucoma in women; and glaucoma, corneal diseases, and DRP in men. The differences in these results may be related to changes in demographic properties.

In a study conducted in Somalia, the most causes of unilateral blindness were trauma complications, cataracts, and DRP, respectively. The most causes of bilateral blindness were cataracts, DRP, and glaucoma. In this study, the effects of trauma were due more to geographical reasons (7). In our research, the most common cause of unilateral blindness in men and women was AMD, similar to developed countries. Other causes included ocular diseases. The most common causes of bilateral blindness, other than AMD, were DRP and optic nerve diseases.

A meta-analysis that analyzed data from studies in six regions and 39 countries worldwide reported that the most frequent causes of blindness were cataracts (51\%), glaucoma (8\%), and AMD (5\%) (11). In our study, blindness due to cataracts ranked 7 th with $3.8 \%$. These results may be due to the early admission, diagnosis, and treatment of cataracts patients. In developing countries, the delay in cataracts operations may result in underestimation of the rates of AMD.

Our study has several limitations. First, the socioeconomic levels of the study groups were not known or evaluated. Grouping the patients according to their socioeconomic status, would have provided additional data. Another feature of this study was the limited number of patients that prevented the results from being generalized to society.

In conclusion, the most common cause of both unilateral and bilateral blindness in both genders was AMD. The other leading causes were DRP in females and glaucoma in males. In both the presenile and senile groups, the primary cause of blindness was AMD. We believe that determining the factors that cause blindness in different age and gender groups might guide individual, cultural, and socioeconomic diagnosis, and treatment strategies.

\section{Conflicts of interest}

The authors of this article state that they have no conflict of interest. 


\section{REFERENCES}

1. World Health Organization, Blindness and vision impairment. [Internet] Available from: https:// www.who.int/health-topics/blindness-and-visionloss\#tab=tab_1. Accessed: 27.12.2020.

2. Frick KD, Foster $A$. The magnitude and cost of global blindness: an increasing problem that can be alleviated. American Journal of Ophthalmology 2003;135(4):471-6. (PMID: 12654362).

3. Tunay ZÖ, İdil A, Petriçli í, Özdemir Ö. Low Vision Rehabilitation in Older Adults. Turk J Ophthalmol 2016;46:118-22. (PMID: 27800274) (in Turkish).

4. World Health Organization. Blindness: Vision 2020-The Global Initiative for the Elimination of Avoidable Blindness. Action plan 2006-2011. [Internet] Available from: https://apps.who.int/iris/ handle/10665/43754 9789241595889_eng.pdf. Accessed: 07.01.2021.

5. Şahlı E, İdil A. A Common Approach to Low Vision: Examination and Rehabilitation of the Patient with Low Vision. Turk J Ophthalmol. 2019; 30;49(2):89-98. (PMID: 31055894) (in Turkish).

6. Ceyhan D, İdil AM. Blindness and Low Vision Epidemiology and Organization. Turkiye Klinikleri J Ophthalmol-Special Topics. 2017;10(1):87-92. (in Turkish).

7. Kalaycı M. Causes of Blindness in the Adult Population in Somalia. Turk J Ophthalmol. 2020; 30;50(5):288-92. (PMID: 33342196). (in Turkish).

8. Sabanayagam C, Cheng CY. Global causes of vision loss in 2015: are we on track to achieve the Vision 2020 target? Lancet Glob Health. 2017;5(12):11645. (PMID: 29032196).

9. Pizzarello L, Abiose A, Ffytche T, et al. VISION 2020: The Right to Sight: a global initiative to eliminate avoidable blindness. Arch Ophthalmol. 2004;122(4):615-20. (PMID: 15078680).
10. Bourne RRA, Flaxman SR, Braithwaite $T$, et al and Vision Loss Expert Group. Magnitude, temporal trends, and projections of the global prevalence of blindness and distance and near vision impairment: a systematic review and meta-analysis. Lancet Glob Health. 2017;5(9):888-97. (PMID: 28779882).

11. Pascolini D, Mariotti SP. Global estimates of visual impairment: 2010. Br J Ophthalmol. 2012;96(5):6148. (PMID: 22133988).

12. Mirza E, Mirza GD, Oltulu R, Okka M, Ozkagnici A. The Frequency and Causes of Blindness in a Rural Region of Central Anatolia of Turkey. Eurasian J Med. 2019;51(3):242-6. (PMID: 31692621).

13. Klaver CC, Wolfs RC, Vingerling JR, Hofman A, de Jong PT. Age-specific prevalence and causes of blindness and visual impairment in an older population: the Rotterdam Study. Arch Ophthalmol. 1998;116(5):653-8. (PMID: 9596502).

14. Esteban JJ, Martínez MS, Navalón PG, et al. Visual impairment and quality of life: gender differences in the elderly in Cuenca, Spain. Qual Life Res. 2008;17(1):37-45. (PMID: 18026851).

15. Zetterberg M. Age-related eye disease and gender. Maturitas. 2016 ;83:19-26. (PMID: 26508081).

16. Khanna RC, Marmamula S, Pendri P, et al and Andhra Pradesh Eye Disease Study Group. Incidence, incident causes and risk factors of visual impairment and blindness in a rural population in India: 15 year follow up of The Andhra Pradesh Eye Diseases Study. Am J Ophthalmol. 2020; 29:S0002-9394(20)30533-X. Epub ahead of print. (PMID: 33007274).

17. Doyal L, Das-Bhaumik RG. Sex, gender and blindness: a new framework for equity. BMJ Open Ophthalmol. 2018;1;3(1):e000135. doi: 10.1136/bmjophth-2017-000135. (PMID: 30246151).Causes of unilateral and bilateral blindness of males and females. 